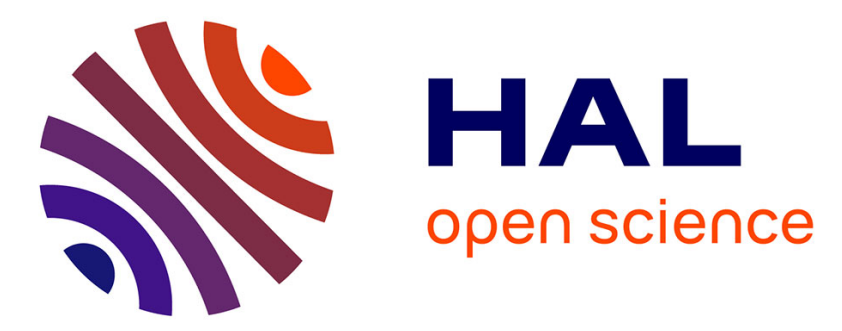

\title{
Bond Graph Modelling and Energy Flow Analysis of a Reach Stacker
}

Thomas Schaep, Wilfrid Marquis-Favre, Eric Bideaux, Eric Noppe, Pierre Rodot, Jean-Christophe Bernigaud, Vincent Langlois

\section{To cite this version:}

Thomas Schaep, Wilfrid Marquis-Favre, Eric Bideaux, Eric Noppe, Pierre Rodot, et al.. Bond Graph Modelling and Energy Flow Analysis of a Reach Stacker. FPNI, Jun 2014, Lappeenranta, Finland. pp. V001T04A003; 9 p., 10.1115/FPNI2014-7833 . hal-01399015

\section{HAL Id: hal-01399015 https://hal.science/hal-01399015}

Submitted on 15 Apr 2019

HAL is a multi-disciplinary open access archive for the deposit and dissemination of scientific research documents, whether they are published or not. The documents may come from teaching and research institutions in France or abroad, or from public or private research centers.
L'archive ouverte pluridisciplinaire HAL, est destinée au dépôt et à la diffusion de documents scientifiques de niveau recherche, publiés ou non, émanant des établissements d'enseignement et de recherche français ou étrangers, des laboratoires publics ou privés. 


\section{BOND GRAPH MODELLING AND ENERGY FLOW ANALYSIS OF A REACH STACKER}

\author{
Thomas Schaep \\ Wilfrid Marquis-Favre \\ Eric Bideaux \\ Laboratoire Ampère \\ INSA Lyon \\ Université de Lyon \\ Lyon, France \\ firstname.name@insa-lyon.fr
}

\author{
Eric Noppe \\ Laboratoire Roberval \\ Université de Technologie \\ de Compiègne (UTC) \\ Compiègne, France \\ eric.noppe@utc.fr
}

\author{
Pierre Rodot \\ Jean-Christophe Bernigaud \\ Vincent Langlois \\ Terex Cranes France \\ Montceau-les-Mines, France \\ firstname.name@terex.com
}

\begin{abstract}
This study focuses on the global energy flow analysis along the three main energy lines of an off-highway vehicle used on port areas called a reach stacker. In order to characterize the energy consumption of the power train and the actuation system, a model of the machine has been established using the bond graph methodology. This language is suitable for representing multi domains energy transfers and allows the determination of the needed energy for an actuator to perform a given task. The simulation results are then compared with measurements carried out on a real reach stacker. Those data help to identify several parameters like friction coefficients and efficiencies. The energy flow analysis also gives detailed information on the main energy losses sources which prefigures coming evolutions.
\end{abstract}

\section{NOMENCLATURE}

$A(x) \quad$ Cross sectional area

$C_{q}$ Discharge coefficient

$\Delta p \quad$ Pressure differential

$F_{\text {roll }} \quad$ Rolling resistance force

$k_{1} \quad$ Rolling resistance slope coefficient (unloaded)

$k_{2} \quad$ Rolling resistance intercept

$k_{3} \quad$ Rolling resistance slope coefficient (loaded)

load Load carried by the machine

loade $_{e}$ Operator accelerator pedal position

$Q$ Hydraulic flow

$\rho$ Hydraulic fluid density
$T_{e, \max } \quad$ ICE maximum torque

$V_{\text {stacker }} \quad$ Reach stacker speed

$W_{e} \quad$ ICE rotation speed

$x \quad$ Valve spool displacement

\section{INTRODUCTION}

Until recently the off-highway vehicles were not hardly subjected to environmental restrictions like fuel consumption or particle emissions reductions and the legislations were rather focused on on-highway vehicles. However the recent norms like Tier IV standards associated with a constant rising fuel cost lead the heavy machinery manufacturers to increase the efficiency of their products while maintaining the performances.

Those machines often work with low efficiency powertrain associated with several high power actuators like hydraulic pumps or cylinders whose energy is distributed by traditional proportional valves characterised by high pressure losses. Some improvements like lock-up clutch for torque converters [?,?] or load sensing systems [?] for hydraulic pumps are more and more implemented but energy recovery issues remain often theoretical. Important improvements would necessarily involve a global energy flow review to achieve an efficient power management. Those new architectures have to provide a better fuel efficiency through potential and/or kinetic energy recovery but also through an optimal control coupled with an optimal sizing of the components.

A reach stacker (Fig.1) has been chosen as a reference ma- 
chine. It is dedicated to handle and move containers on port areas or on transport hubs. This type of machinery has already been subjected to energy flow studies in [?] however no comparison with a real reach stacker was presented. In this paper the simulation results are compared with measurements performed on a reference machine in order to set a work basis providing the possibility to test new components and control strategies being as realistic as possible. The main purpose of this paper is to present a global energy analysis of the chosen machine. The part II deals with the bond graph modelling methodology [?, ?, ?] preceded by a detailed presentation of the machine. The part III aims to present simulation results which are then compared with measurements. Potential improving points will be presented in the fourth part.

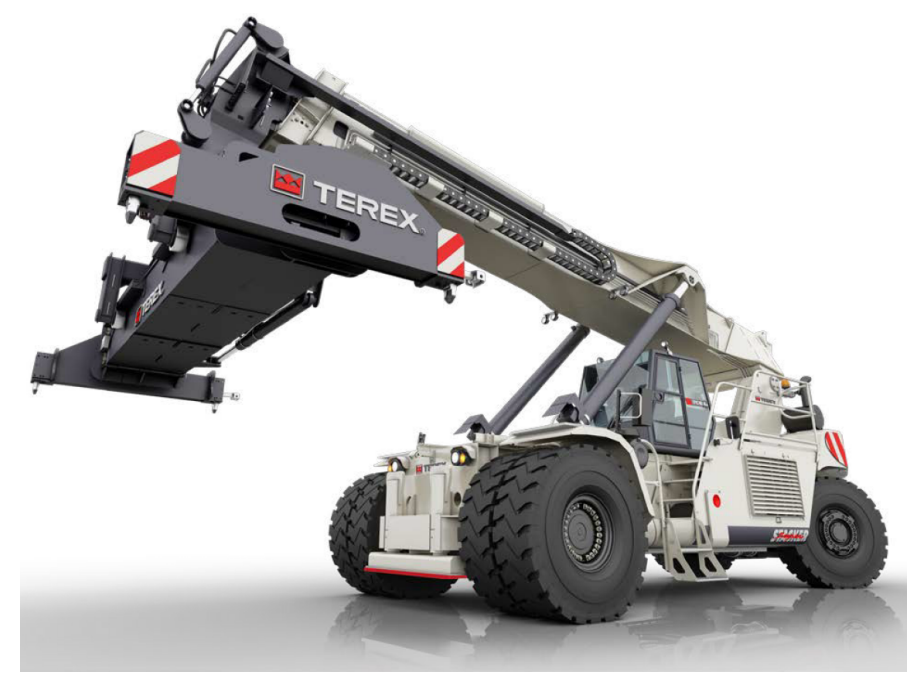

FIGURE 1. OVERVIEW OF A REACH STACKER

\section{Physical modelling \\ II.1. Reach stacker description}

Reach stackers are mobile machines capable of carrying containers up to 45 tons to a height of five standard containers and 35 tons in sixth height. Figure 2 shows a typical maximal load range of container stacking. The machine is composed of four actuating lines permitting it to translate itself, lock and lift the container in order to move it to its next place. We can mention the powertrain composed of an Internal Combustion Engine (ICE) on which is coupled a torque converter and an automatic gearbox driving the energy to the front axle. The ICE also drives two hydraulic pumps both equipped with a Load Sensing (LS) system. The hydraulic fluid is supplied to the lifting and telescoping cylinders via two proportional valves. Finally the spreader interfaces the machine with the container with a twist-lock system.



FIGURE 2. MAXIMUM LOAD CHART

In this paper bond graphs are used to model the dynamic behaviour of each component making part of the high power system. This language is particularly adapted for modelling mechatronic systems with several energy domains since it uses power bonds between physical phenomena to describe the system dynamics. Those power bonds are the result of the product of an effort with a flow. The bond graph model has been split into three separate submodels (Fig. 3) which are detailed in the following paragraphs. All submodels have been implemented into the bond graph modelling software MS1, which permit to integrate the control with the physical model.

Auxiliary components like steering system or spreader actuators are neglected insofar as their energy consumption is much lower than the other actuator energy needs. Thus are selected the powertrain, the lifting and telescoping system to be modelled. Finally a multi-body dynamic model is also established in order to represent accurately the behaviour of the machine. Table 1 shows some important features of the selected reach stacker.

\section{II.2.1. Powertrain}






FIGURE 3. LAYOUT OF THE SUBMODELS SPLITTING

TABLE 1. POWERTRAIN AND HYDRAULIC FEATURES

\begin{tabular}{cll}
\hline Element & Feature & Value \\
\hline Engine & Max. power & $257 \mathrm{~kW}$ \\
& Max. torque & $1790 \mathrm{~N} . \mathrm{m}$ at \\
& & $1200 \mathrm{rpm}$ \\
Torque converter & Torque ratio at stall & 2.3 \\
Gearbox & Gear number & 4 \\
Wheels & Diameter & $1.6 \mathrm{~m}$ \\
Pump 1 & Max. displacement & $145 \mathrm{cc}$ \\
Pump 2 & Max. displacement & $145 \mathrm{cc}$ \\
Lifting cylinder & Max. pressure & $420 \mathrm{bar}$ \\
Telescoping & Max. pressure & $350 \mathrm{bar}$ \\
cylinder & & \\
\hline
\end{tabular}

The ICE can be modelled completely with combustion phenomena but this would imply an additional complexity which is not relevant in our case. The relatively slow dynamics of the engine allows this assessment, thus we prefer to model it simply by a torque source and take into account its inertia and shaft stiffness [?].The torque is calculated as a function of the engine speed, the corresponding maximum torque and the engine load (Eqn. (1)). The maximum torque comes from the characteristic curve given by the manufacturer and then compared with measurements carried out on the machine by applying maximum load on the engine at different working speeds.

$$
\text { Torque }=f\left(W_{e}, T_{e, \max }, \text { load }_{e}\right)
$$

As the ICE is coupled on one side with the powertrain and on the other side with the hydraulic pumps, we can see in Fig. 4 that the corresponding bond graph model split the energy flow into two lines.



FIGURE 4. BOND GRAPH MODEL OF THE ICE

The ICE drives a torque converter which is a fluid coupling device having two functions: clutch and torque multiplication. It is composed of three parts known as impeller, turbine and stator. The impeller which is driven by the ICE works as a pump giving kinetic energy to the fluid. This kinetic energy is then transferred to the turbine via its blades. The stator redirects the fluid flow after the turbine reducing the torque needed by the impeller to accelerate the fluid. This phenomenon generates the torque multiplication. The physical model (Fig. 5) takes into account the different losses due to fluid friction and shocks and the complete bond graph modelling methodology is explained in [?]. All parameters have been correlated with experimental data via an optimisation tool.

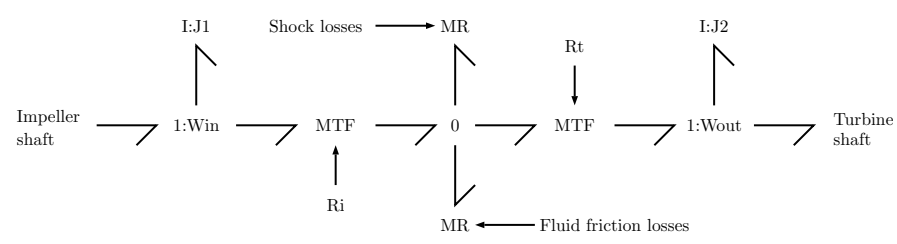

FIGURE 5. BOND GRAPH MODEL OF THE TORQUE CONVERTER

The gearbox is much simpler and is modelled with a modulated transformer [?] representing the gear ratio. The efficiency is considered constant and represented by a dissipation element $R$. 
The rolling resistance was directly deduced from the measurements conducted on a real reach stacker for the unloaded and loaded cases. A mathematical function of the resistant force can be expressed for each situation by the following equations:

$$
\begin{aligned}
& F_{\text {roll }}=k_{1} \cdot V_{\text {stacker }}^{3 / 2}+k_{2}(\text { if load }=0) \\
& F_{\text {roll }}=k_{3} \cdot V_{\text {stacker }}^{3 / 2}+k_{2}\left(\text { if load }=27 \cdot 10^{3} \mathrm{~kg}\right)
\end{aligned}
$$

We can also notice that aerodynamic forces have been neglected due to the low maximum speed of the reach stacker.

\section{II.2.2. Hydraulic circuit}

The hydraulic circuit has been quite simplified to keep only the highest energy consumers, namely the lifting and telescoping systems. We can notice on Fig.7 that both lifting and telescoping circuit have regeneration valves (Fig. 7 (4)) which are only used when unloaded. Instead of dissipating the hydraulic energy outgoing from the cylinder the flow is redirected to the main chamber reducing the needed flow rate to achieve the same task. In loaded phases the reached pressure in the piston chambers would be too high to keep this working mode that is why the rod chamber is connected to the tank forcing a low pressure.

Two pumps (Fig. 7 (1)) are driven by the ICE in order to transform the rotational mechanical energy into hydraulic energy. The load sensing system of each pump adapts its displacement to keep a preset pressure differential across the valves constant. The pressure information which transmits no energy is directly transmitted to the pump and keeps the highest pressure between the lifting and telescoping circuit via three shuttle valves. When the cylinders are unloaded the displacement of each pump reduces to adapt its flow rate. Conversely when the actuators are loaded the pressure rises and the displacement increases to keep the pressure differential between the pump and the circuit constant. The dynamics of the pump displacement controller is taken into account and volumetric and mechanical efficiencies are applied as functions of the pressure to model accurately the energy losses.

The two proportional valves (Fig. 7 (2)) controlling the hydraulic energy distribution to the lifting and telescoping cylinders are piloted by the operator via a joystick whose position controls low pressure regulators at each side of the valves. Two springs are also present to counteract the pressure force and produce a displacement proportional to the control pressure. The model does not take into account this physical part by considering the energy consumed by this subsystem negligible compared with the rest of the system. Instead, the spool displacement is directly piloted by a non powered signal given by a signal source. To this displacement corresponds a cross sectional area inducing a hydraulic flow (Eqn. (3)).

An important element to be mentioned is the flow regulator [?] (Fig. 7 (3)) added to the lifting circuit to control the lowering speed especially in loaded case. The hydraulic pressure is fully dissipated in this valve to maintain a maximal predefined lowering speed. We can instinctively deduce that a big part of the hydraulic energy is lost in this valve. The flow through the valve depends on several parameters like the cross sectional area or the pressure differential:

$$
Q=C_{q} A(x) \sqrt{\frac{2 \Delta p}{\rho}} \operatorname{sign}(\Delta p)
$$

The function $\mathrm{A}(\mathrm{x})$ represents the cross sectional area and depends on the spool position $\mathrm{x}$. Thus it is possible to control the flow rate by choosing the right spool position. The principle is the same as the load sensing system insofar as we want to control the pressure differential across the valve to reach the desired flow rate. In bond graph language the flow control is done through energy dissipation elements and the complete model can be seen on Fig. 6.

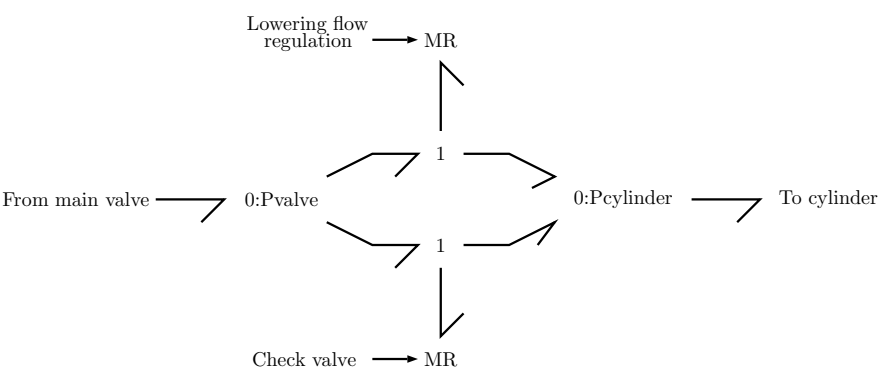

FIGURE 6. BOOM LOWERING CONTROL VALVE

The telescoping circuit has the particularity of being provided with a balancing valve (Fig. 7 (5)) at the piston chamber side of the cylinder. This components aims to avoid an untimely stick-slip effect caused by the friction between the two telescoping bodies. In fact the valve enforces a high pressure in the rod chamber by limiting the flow rate going out of the piston chamber.

The last noteworthy point to be presented in this section is the modelling of the cylinders (Fig. 7 (6)). As those actuators are working with substantial fluid volumes the compressibility is here considered as a significant physical phenomenon and is therefore modelled. The bond graph model [?] of such phenomenon is a capacitance with one mechanical domain port and one fluid domain port ensuring the energy conservation principle. Thermal effects are nevertheless neglected due to their low impact on the system. 




FIGURE 7. HIGH PRESSURE HYDRAULIC CIRCUIT

\section{II.2.3. Multi-body dynamic model}

The powertrain and the hydraulic models presented in the two previous sections are linked together via a multi-body dynamic model composed of kinematic joints as well as masses and inertias for each body. The modelling steps of the multi-body dynamic model are not presented here but some important assumptions are nevertheless outlined in the following paragraph.

The revolute joints are considered without friction unlike the boom prismatic joint on which a dumping phenomenon is taken into account. A specific study has indeed been led to model the friction forces that appear on the contact area between the two boom components during telescoping in and out phases. Measurements have been conducted on a reach stacker for three boom angles and two loads permitting to build a friction cartography. The simulation program uses linear interpolation to find the friction force depending on the boom angle, the boom position and the container weight.

\section{Simulation results \\ III.1. Standard duty cycle}

In order to represent accurately the common use of the machine a duty cycle has been set. The reach stacker can be used in different ways but the most repeated task is unstacking and stacking containers from one place to another like unloading a truck and stacking the container in the storage area or the contrary (Fig. 8). This standard mission profile will also give the possibility to compare several architectures with the same constraints (not presented in this paper). The working cycle chosen for the energy flow analysis simulates a truck unloading followed by a stacking step on fifth container height and second row. This situation is more disadvantageous compared with an unstacking cycle where the container is already elevated.

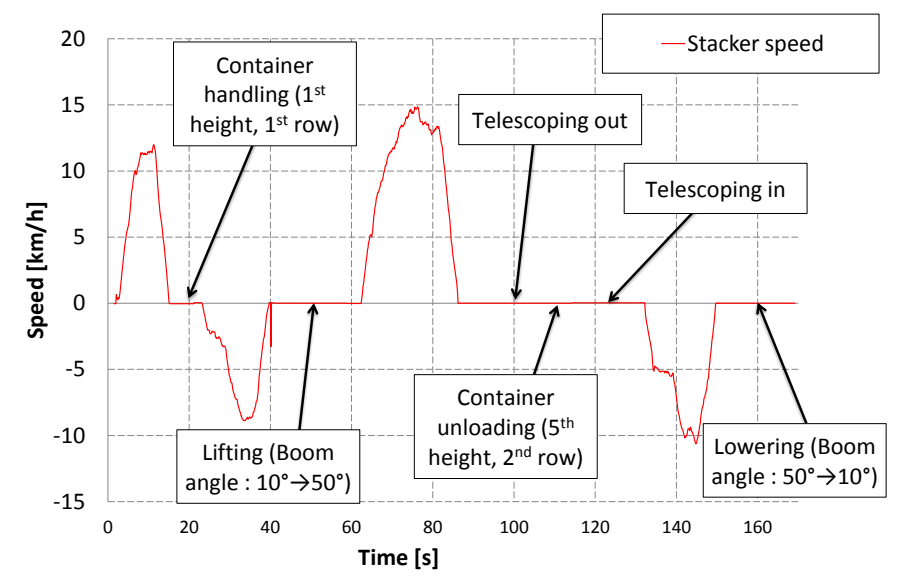

FIGURE 8. TRUCK UNLOADING DUTY CYCLE

\section{III.2. Results}

Table 2 shows the energy dissipation repartition between several components. The primary energy corresponds to the energy going out from the engine to the transmission shaft plus the pumps shaft simulated with the previously detailed standard duty cycle.

\section{III.2.1. Powertrain}

The rolling resistance represents the main source of energy dissipation due to the six wheels (wide contact area) and the heavy weight of the machine. The rolling resistance depends largely on the mass but reducing the counterweight at the rear of the machine would reduce the maximum liftable container weight and therefore would decrease the performances in a way that is not admissible. As shown in Fig. 10 the power expended to counteract the rolling resistance largely increases when the reach stacker is loaded.

We can also notice that the friction brake system converts almost $17 \%$ of the primary energy into heat. This heat is then evacuated through a specific oil circuit and a heat exchanger that are not modelled here. Recovering the braking energy in its entirety would be hard given the high braking power but only a part 
TABLE 2. ENERGY DISSIPATION DISTRIBUTION

\begin{tabular}{clc}
\hline Power line & Element & Primary energy rate \\
\hline Powertrain & Torque converter & $10.2 \%$ \\
& Gearbox + Axle & $6.5 \%$ \\
& Rolling resistance & $21.1 \%$ \\
& Braking & $16.9 \%$ \\
$\begin{array}{c}\text { Hydraulic } \\
\text { line }\end{array}$ & Pumps & $4.2 \%$ \\
& Lifting circuit & $9.2 \%$ \\
& Telescoping circuit & $8.1 \%$ \\
$\begin{array}{c}\text { Multi-body } \\
\text { dynamics }\end{array}$ & Boom friction & $5.5 \%$ \\
\hline
\end{tabular}

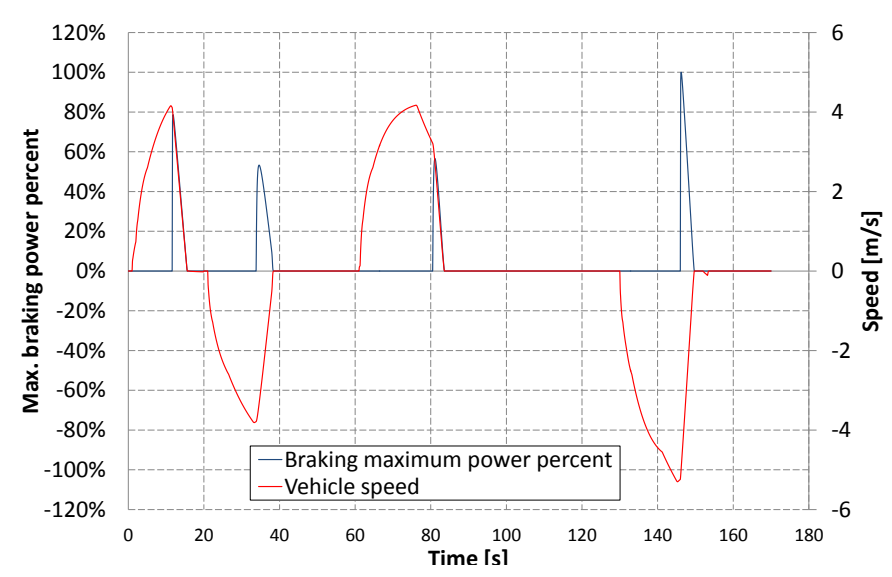

FIGURE 9. BRAKING DISSIPATED POWER

would have a double benefit: the primary energy need would be reduced by the back flow of braking energy but also by the down sizing of the cooling system, although this circuit does not consume much energy.

The last point of this section deals with the comparison between simulations and measurements. A numerical model of a physical system can indeed be a good way to verify the good operating of the real one. The comparison between measurements and simulation permitted to highlight a dysfunction in the powertrain and particularly with the torque converter. The characteristic curve of the traction force as a function of the vehicle speed for a similar powertrain presented in [?] shows that the torque multiplication of the torque converter at stall is typically between 2 and 3.5 and produces a torque peak at low speed. Figure 11

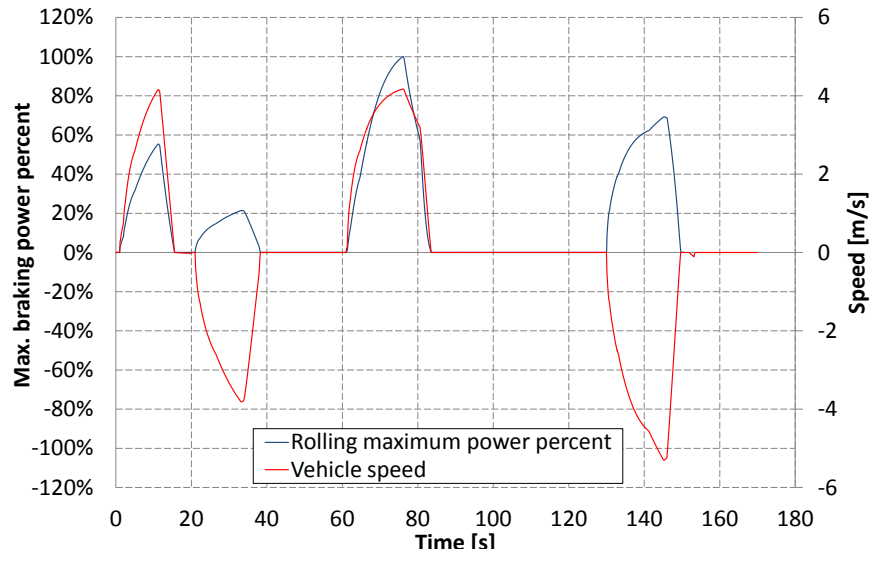

FIGURE 10. ROLLING DISSIPATED POWER

presents the normalised traction effort applied on the machine for simulation and measurements and we can easily see that the measured traction force is much lower than the simulation from $0 \mathrm{~km} / \mathrm{h}$ to $6 \mathrm{~km} / \mathrm{h}$. As the typical working cycle of the machine is composed of a lot of starts and stops the torque converter is subjected to an important reduction of its global efficiency (0.49) compared with the simulated torque converter efficiency $(0.81)$.

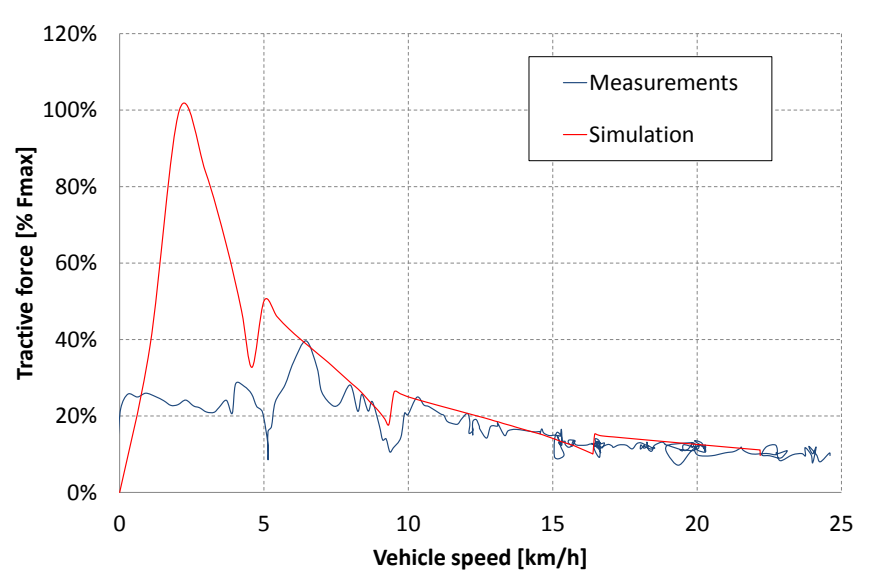

FIGURE 11. TRACTIVE FORCE

\section{III.2.2. Handling functions}

Figure 12 shows the energy transferred from the ICE to the pumps shaft during the duty cycle. The evolutions of measurements and simulation are relatively close meaning that the energy dissipation as well as the multibody dynamic model fit with the reality. 
Energy losses that occur inside the hydraulic circuit represent $21 \%$ of the primary energy, coming from pump mechanical and volumetric efficiencies but also and mainly from pressure losses when the fluid go through the valves and the pipes. We can for instance focus on the Fig. 13 which shows the pressure at the outlet of the pump and inside the piston chamber of the lifting cylinders for measurements and simulation. The lifting phase begins at $5 \mathrm{~s}$ and stops at about $30 \mathrm{~s}$ in order to lift the boom plus a 27 tons container from 10 degrees to 65 degrees. We can firstly notice that the simulation results are similar to the measurements which validate this part of the hydraulic model. Secondly, we can observe a constant pressure drop between the pump pressure and the actuator pressure of about 50 bars.

In case of a boom lowering with no load the potential energy accumulated in elevation is completely transformed into heat in the control valve and uses 5.5\% of the primary energy. The stacking duty cycle has no lowering phase when loaded reducing the potential energy lost into the control valve. In that case the dissipated energy is 4.5 times greater than in unloaded case meaning that the recoverable energy would be non negligible.

The telescoping circuit also dissipates ca. 5.5\% during rod retraction because the piston chamber pressure is fully transformed into heat in the balancing valve. Reducing the pressure in the piston chamber would decrease the pressure in the rod chamber as well as the wasted energy, but the stick-slip phenomenon prevent us at the moment from modifying the calibration of the balancing valve. Figure 14 shows the pressures inside the piston chamber and rod chamber of the telescoping cylinder together with the pump pressure during the boom extension with a container of 27 tons (boom angle $=43 \mathrm{deg}$ ). Simulation and measurements fit relatively well and this part of the model can also be validated. The average pressure drop between the pumps and the cylinder is about 22 bars which is far less than the lifting circuit for a similar pump flow rate $(456 \mathrm{~L} / \mathrm{min}$ for the Fig. 13 and $527 \mathrm{~L} / \mathrm{min}$ for the Fig. 14).

We can finally focus on the friction forces that appear on the contact area between the two boom components during telescoping phases. The dissipated energy which is simulated for a loaded telescoping out followed by an unloaded telescoping in counts for $5.5 \%$ of the primary energy. However reducing this wasted energy seems also to be hard since the friction pads are already made of a nylon plastic providing a low friction coefficient combined with a good mechanical strength.

\section{III.2.3. ICE}

The ICE is characterised by its specific consumption which is the amount of fuel needed to produce one kilowatt hour at the engine shaft. This parameter depends mainly on the rotation speed and the load, that is why engine manufacturers often express the specific fuel consumption as a function of the engine speed and torque. Thus we are here analysing the working

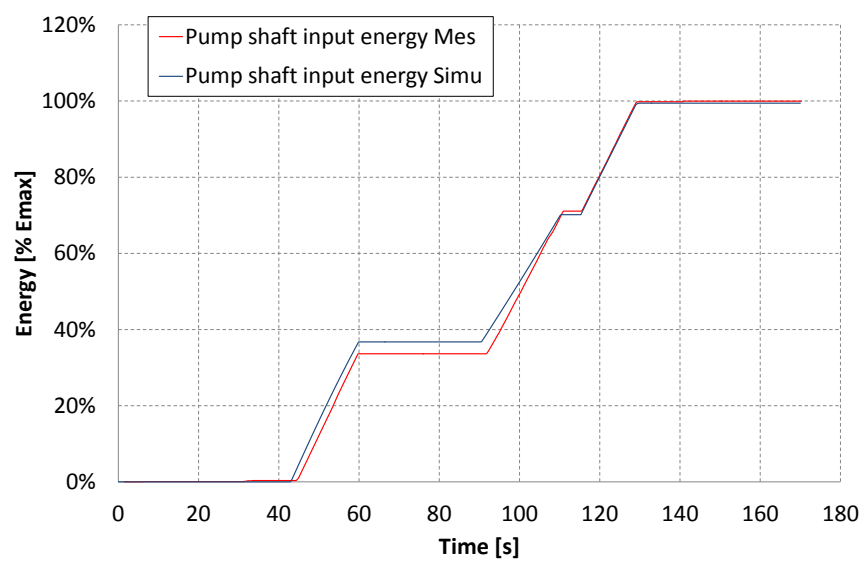

FIGURE 12. PUMPS SHAFT INPUT ENERGY

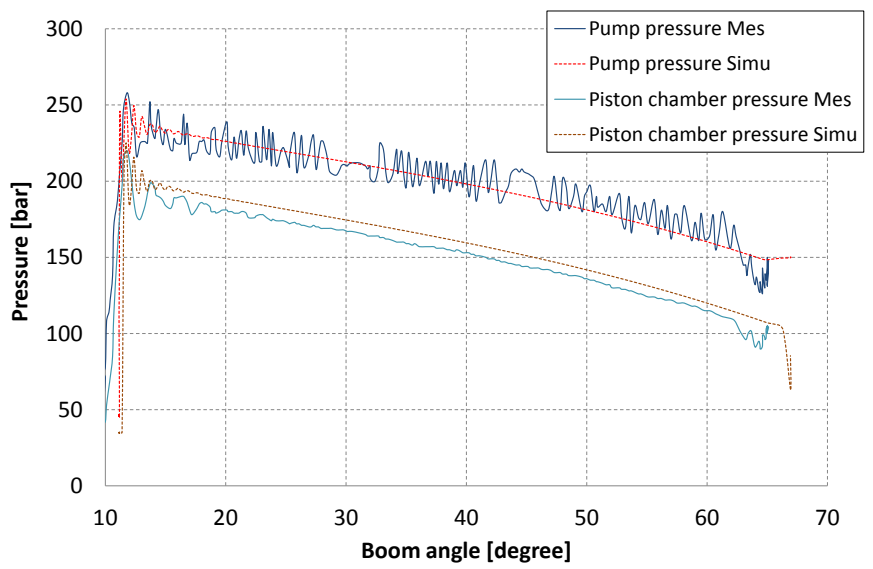

FIGURE 13. PRESSURES AT DIFFERENT POINTS OF THE LIFTING CIRCUIT

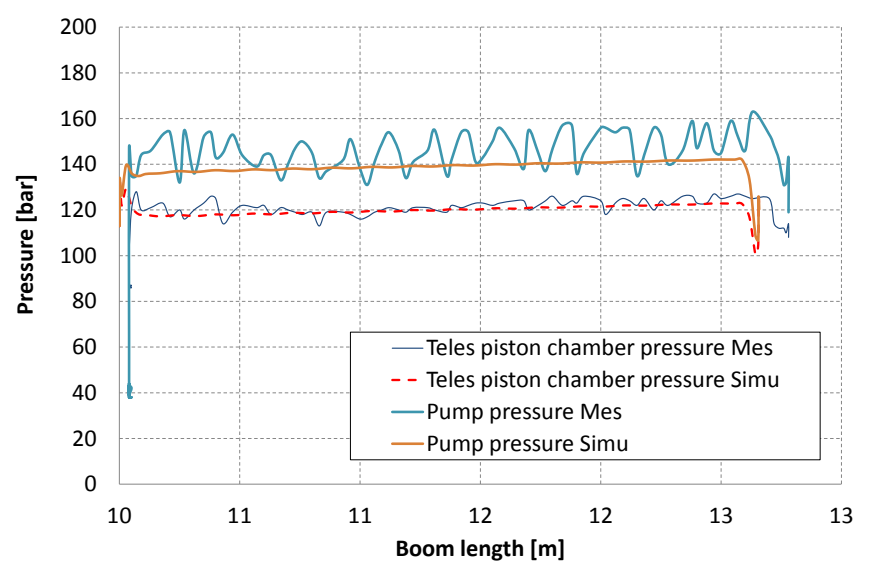

FIGURE 14. PRESSURES AT DIFFERENT POINTS OF THE TELESCOPING CIRCUIT 
points of the engine to evaluate if the engine is functioning in good efficiencies areas or not. In most gasoline engine the best working point is situated at low speed and high torque and in our case at approximatively 1300 RPM. We can see on Fig. 15 that those working points for the stacking cycle are $56 \%$ of the cycle above 1900 RPM. An important point to know before an explanation is given is that the operator always control the engine load via a pedal and not only during translation phases but also during hydraulic actuator driving like boom lifting or telescoping. If the operator press completely the accelerator pedal and the needed torque to perform a given task is below the engine torque fully loaded then the engine control unit limits the fuel injection to maintain a maximum speed rated at approximately 2200 RPM. The needed torque to perform a lifting or a telescoping even loaded is always below the maximum torque explaining the high speed working points.

Translation phases are not fundamentally different particularly when the operator applies a full load on the engine. As the common use of the machine requires a lot of accelerations and brakes the user wants to reach the maximum speed as quickly as possible and therefore applies a full load. Prima facie it is a good way to reach good efficiencies working points but the torque converter induces low speed ratios at low vehicle speeds and leads the engine to work at high speeds.

\section{Perspectives and future work}

As detailed in section III.2.1. the powertrain is the greatest energy consumer and wastes ca. 54\% of the primary energy. However the rolling resistance takes a front seat role $(21 \%$ out of the 54\%) and this energy is non recoverable. Some evolutions are nevertheless possible to recover the braking energy like in [?] where the authors present a power split transmission (PST) combined with a displacement controlled (DC) actuation allowing a reach stacker to save theoretically $38 \%$ fuel. The total or partial decoupling of the ICE and the powertrain will be studied and its potential energy consumption gain will be evaluated. In [?] a state of the art of hybrid hydraulic systems applied to forest harvester is presented and more specifically technological solutions to recover wasted energy from powertrain or actuation components. Different storage systems and power architectures are also compared. A big focus will be done on the choice of the components but the main work will be to find the optimal control strategies combined with the best architecture in order to find a global optimum with given objectives. To do this the mathematical model presented in this paper will be used as reference and adapted for each tested architecture.

\section{Conclusion}

This paper presented the energy flow analysis of a reach stacker which is the first step of the global optimisation since
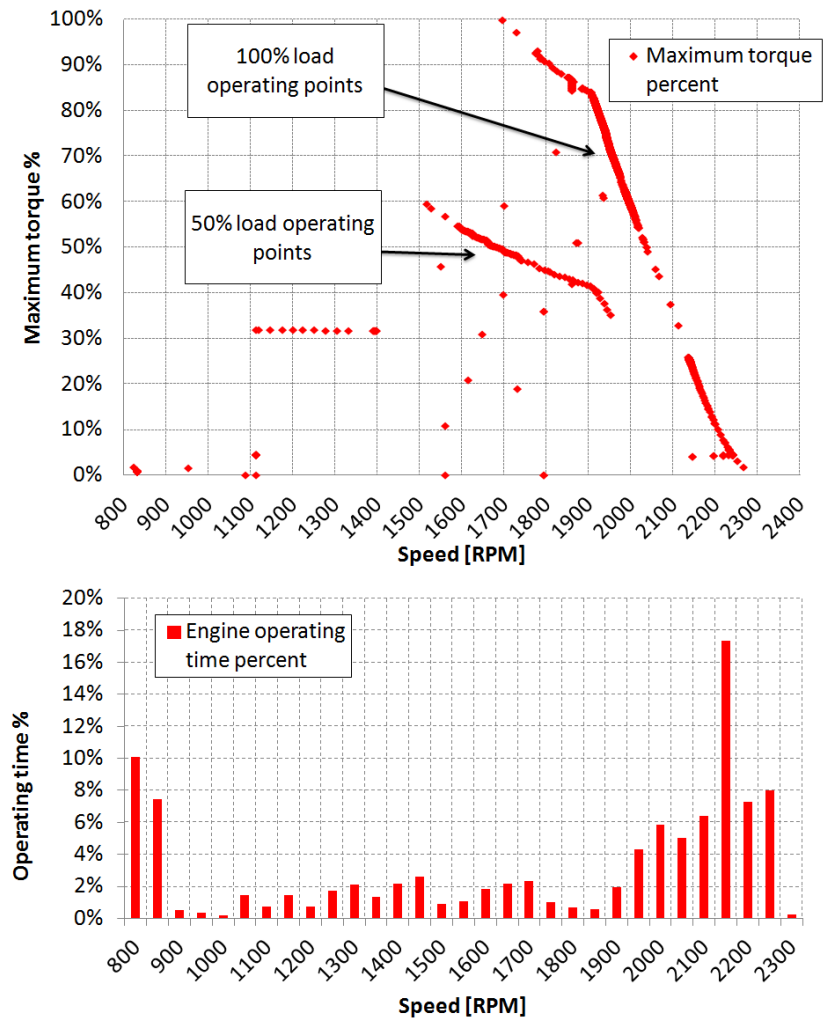

FIGURE 15. ICE WORKING POINTS DISTRIBUTION

it allows us to understand accurately how, where and when the energy is wasted. To do that a physical model of the machine has been established and correlated with measurement performed on a reference machine. The comparison between simulations and measurements highlighted a dysfunction of the torque converter. Furthermore this analysis permits to evaluate the performances of each component and to take a critical look on control strategies particularly regarding the ICE control. Braking and lowering energy recovery could be a good way to reduce the fuel consumption but other solutions exist like decoupling the ICE and the powertrain for instance. The mathematical model also aims to set a working basis for testing new solutions with a good reliability on the reality.

\section{ACKNOWLEDGMENT}

The authors would like to thank the industrial collaborator Terex Cranes taking part in this project by supporting and sharing data. 